\title{
Penggunaan Media Pembelajaran Geometri Berbasis Etnomatematika
}

\author{
Wiwin Sumiyati ${ }^{1}$, Netriwati ${ }^{1}$, Rosida Rakhmawati ${ }^{1}$ \\ 1 Jurusan Pendidikan Matematika, Universitas Islam Negeri Raden Intan Lampung. Jalan Let. Kol. \\ H. Endro Suratmin Sukarame Bandar Lampung 35133, Indonesia. \\ * Corresponding Author . E-mail: wiwinsumiyati123@gmail.com
}

Received : 09-11-2017; Revised : 05-01-2018; Accepted : 29-01-2018

\begin{abstract}
Abstrak
Mencari tahu pengaruh belajar geometri menggunakan media belajar berbasis etnomatematika untuk kemampuan berpikir kritis matematis (critical thinking) merupakan tujuan dari penelitian ini. Penelitian ini adalah penelitian eksperimen dengan metode penelitian kuantitatif. Menggunakan rancangan posttest-only design dalam penelitian ini. Populasinya ayitu kelas control dan ekperime. Metode tes, wawancara dokumentasi dan observasi merupakan tehnik pengumpulan data yg digunakan. Caranya yaitu media Power Point 2016 untuk kelompok eksperimen dan pembelajaran konvesional untuk kelompok kontrol dengan. Hasilnya adalah bahwa perbedaan terjadi antara yangd apat media belajar etnomatematika dan yang tidak dapat media belajar (konvensional). Rata-rata nilai eksperimen sebesar 86,57 dengan varians sebesar 77,57 sedangkan rata-rata nilai kontrol sebesar 77,33 dengan varians 133,50 , didapat $t_{\text {hitung }}$ sebesar 3,138, dengan $t_{\text {tabel }}$ sebesar 2,011. Berdasarkan uji hipotesis bahwa $t_{\text {hitung }}>t_{\text {tabel }}$ dengan taraf siginifikan $\alpha=0,05$ maka dapat disimpulkan terdapat pengaruh media pembelajaran geometri berbasis etnomatematika terhadap kemampuan berpikir kritis matematis siswa.
\end{abstract}

Kata kunci: Bahan ajar, Etnomatematika, Kemampuan Berpikir Kritis

\begin{abstract}
Finding out the influence of learning geometry using ethnomathematics-based learning media for critical thinking ability (critical thinking) is the purpose of this study. This research is experimental research with quantitative research method. Using the posttest-only design in this study. Its population is the control and experimental class. Test methods, documentation and observation interviews are the data collection techniques used. The way is the PowerPoint 2016 media for the experimental group and conventional learning for the control group with. The result is that the differences occur between the apart media and the learning of ethnomathematics that cannot be media learning (conventional). The average experimental value of 86.57 with a variance of 77.57 while the average control value of 77.33 with a variance of 133.50, obtained t count of 3.138, with ttable of 2.011. Based on hypothesis test that $t_{\text {hitung }}>t_{\text {table }}$ with significance level $\alpha=0,05$ hence can be concluded there is the influence of media of learning of geometry based on ethnomathematics to students critical thinking ability of mathematical.
\end{abstract}

Keywords: Critical Thinking Skills, Ethnomatematics, Teaching materials. 
Desimal, 1 (1), 2018 - 16

Wiwin Sumiyati, Netriwati, Rosida Rakhmawati

\section{PENDAHULUAN}

Untuk menyambut masa depan hendaknya kita berbenah diri dengan memanfaatkam perkembangan ilmu dan tehnologi (Sukring, 2016). Karena pada umumnya masa depan kita adalah tujuan hidup agar yang akan kita capai. Namun tak akan seutuhnya kita miliki masa depan tanpa melalui pendidikan.

Mewujudkan suasana belajar dan proses belajar-mengajar agar secara aktif potensi diri peserta didik dapat dikembangkan untuk memiliki kepribadian, kecerdasan, serta keterampilan yang diperlukan dirinya dan masyarakat (Yusnita, Masykur, \& Suherman., 2016). Selain itu menurut Bukunola dalam Santi Widyawati pendidikan merupakan cara dalam mengenalkan pada manusia untuk memiliki pengetahuan dan sikap yang lebih baik terlebih lagi belajar matematika yang didalam ada sifat tanggung jawab (Widyawati, 2017).

Pelajaran Matematika merupakan pelajaran yang terstruktur, terorganisasi, dan berjenjang, artinya adanya kaitan antara materi. Memecahkan maslah Dalam pembelajaran matematika itu yang paling penting, bahkan sebagai jantungnya matematika (Yuliyanto \& Jailani, 2014). Karena memahami konsepnya saja atau prosedurnya saja tidaklah cukup dalam belajar matematika, (Putra, 2017). Akan tetapi sudah terlalu umum pembelajaran matematika tepusat pada guru sehingga pembelajaran lebih cenderung pasif. Siswa hanya menikmati kejenuhannya dalam pembelajaran matenatika yabg selalu berkutat dengan pembelajaran seperti itu.

Berdasakan observasi yang dilakukan peneliti bahwa dalam belajar matematika umunya peserta didik bersifat pasif, tidak muncul pertanyaan dari peserta didik, tidak menjawab pertanyaan yang disampaikan oleh guru dengan tertib, metode yang dikembangkan guru adalah ceramah dan diselingi dengan tanya jawab, sehingga proses belajar mengajar hanya didominasi oleh guru dan peserta didik yang pandai saja, disamping itu pembelajaran yang dikembangkan bersifat tekstual dengan buku sebagai sumber pembelajaran utama. Media pembelajaran yang paling sering digunakan hanya papan tulis dan alat tulisnya. Proses pembelajaran yang diterapkan adalah pembelajaran dimana guru terlebih dahulu menjelaskan materi yang akan dipelajari, dilanjutkan dengan memberi contoh-contoh soal kemudia siswa diberi latihan soal untuk diselesaikan dan siswa diperbolehkan bertanya jika tidak mengerti. Sistem pembelajaran seperti ini dapat membuat siswa tidak bersemangat untuk mengikuti pelajaran.

Melakukan inovasi terbaru dalam belajar-mengajar yaitu digunakannya media pembelajaran yang tepat bisa saja mengatasi maslah yang sering terjadi. Multimedia digunakan dalam belajarmengajar bisa berguna peserta didik untuk aktif dan fokus dalam belajar. Mereka memperhatikan penuh terhadap materi yang diberikan, karena pada saat persentasi guru tidak lagi menuliskan materi atau contoh soal di papan tulis,. Pembelajaran matematika menggunakan dengan menggunakan media pembelajaran sangat bermanfaat untuk merangsang penglihatan dan gaya gerak siswa. Media pemebelajaran dapat respon yang baik dari siswa (Sari, Farida, \& Putra, 2017). Merujuk hal tersebut m,aka penelitian dengan digunakannya media pembelajaran menjadi ketertarikan tersendiri bagi peneliti.

Berdasarkan kurikulum 2006, porsi yang sangat besar didapatkan pada pelajaran geometri pada jenjang SMP jika diibandingkan dengan beberapa materi yang lain. Hal ini mengindikasikan bahwa geometri metri merupakan salah satu 
komponen paling penting pada kurikulum matematika (Yuliyanto \& Jailani, 2014). Dalam pembelajaran yang responsif budaya, guru matematika diharapkan mampu mewujudkan matematika sebagai ilmu yang melekat dengan budaya (cultural bounded) dalam pembelajaran. Untuk itu, guru juga perlu memahami latar belakang sosial budaya siswanya. Guru perlu memiliki pengetahuan potensi budaya lokal terkait dengan matematika, memahami pengetahuan matematika yang diperoleh siswa dari kegiatan sehari-harinya dan memiliki keterampilan untuk merancang dan mengembangkan pembelajaran matematika menggunakan budaya. Pembelajaran matematika yang responsif budaya atau yang biasa disebut dengan etnomatematika (Danoebroto, 2016).

Bukanlah hal baru Memasukkan etnomatematika dalam kurikulum, terdirinya berbagai macam suku dan budaya, dan setiap suku di iindonesia memiliki cara tersendiri dalam menyelesaiikan masalah yang diahadapi (Sirate., 2012). Salah satu aplikasi dari pendekatan yang juga masih biasa juga digabungkan dengan pendekatan saintifik yaitu etnomatematika. Dalam proses pendidikan (Edy, 2013).

Kemapuan berpikir kritis matematis adalah kemampuan yang terarah pada tujuan, yaitu menghubungkan kognitif denga dunia luar sehingga mampu membuat keputusan, pertimbangan, tindakan, dan keyakinan (Karim, 2011). Selain itu juga merupakan kemampuan menggunakan pengetahuan lama peserta didik yang dihubungkan dengan permasalahan baru yang sedang dihadapi untuk mendapatkan sebuah kesimpulan dimana, dalam mengambil sebuah kesimpulan diperlukan penalaran yang baik serta mengevaluasi kesimpulan yang telah diperoleh (Manfaat \& Anasha, 2016).

Kebaruan dalam penelitian ini terletak pada ekperimentasi modul

geometri berbasis etnomatematika yang telah dikembangakan guna melihat pengaruhnya terhadap kemampuan berpikir kritis matematis siswa. Modul yang telah dikembangan sebelumnya telah divalidasi dan diuji sesuai langkahlangkah penelitian pengembangan.

\section{METODE}

Metode eksperimen yang menjadi jenis penelitian ini. Desain yang digunakan yaitu Quasi Exsperimental Design. (Sugiyono., 2014). Desain posttestonly design menjadi desain yang digunakan, dengan rancangan desain terlihat pada Gambar 1.

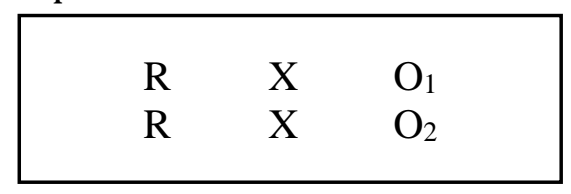

Gambar 1. Desain penelitian

Teknik pengambilan sampel pada penelitian ini dilakukan dengan teknik acak kelas. Teknik pengumpulan data melalui metode tes, metode wawancara, metode dokumentasi, metode observasi.

Teknik analisis data yang digunakan dalam penelitian ini meliputi:

1. Uji Prasyarat Analisis

a. Uji Normalitas,

Yaitu Normal atau tidaknya distribusi yang diiambil. Uji normalitas yang digunakan peneliti adalah uji Lilliefors. (Novalia \& Syazali, 2014).

b. Uji homogenitas,

Gunanya agar kita tau Kedua sampel memiliki variansi atau Uji homogenitas varians yang digunakan adalah uji $F$.

2. Uji Hipotesis

Yaitu uji-T pada taraf $\alpha=0,05$ dengan rumus sebagai berikut:

di mana

$$
t=\frac{\bar{x}_{1}-\bar{x}_{2}}{S_{g a b} \sqrt{\frac{1}{n_{1}}+\frac{1}{n_{2}}}}
$$


Desimal, 1 (1), 2018 - 18

Wiwin Sumiyati, Netriwati, Rosida Rakhmawati

$$
S_{g a b}=\sqrt{\frac{\left(n_{1}-1\right) S_{1}^{2}+\left(n_{2}-1\right) S_{2}^{2}}{n_{1}+n_{2}-2}}
$$

Bandingkan harga $t_{\text {hitung }}$ dengan harga $t_{\text {table }}$ dengan $\mathrm{dk}=n_{1}+n_{2}-2$ dan taraf signifikan $(\alpha)=0,05$. Kriteria pengujian: Jika $\mathrm{t}_{\text {hitung }} \leq \mathrm{t}$ tabel maka dapat disimpulkan tidak ada pengaruh media pembelajaran geometri berbasis etnomatematika terhadap kemampuan berpikir kritis matematis siswa.

Keterangan :

$\bar{x}_{1} \quad=$ Rata-rata nilai kelas eksperimen

$\bar{x}_{2} \quad=$ Rata-rata nilai kelas kontrol

Sgab = Simpangan baku gabungan

$n_{1}$ =Banyaknya siswa kelas eksperimen $n_{2} \quad=$ Banyaknya siswa kelas kontrol

$S_{1}^{2} \quad=$ Varians kelas eksperimen

$S_{2}^{2} \quad=$ Varians kelas kontrol (Sugiyono., 2014).

\section{HASIL DAN PEMBAHASAN}

Data hasil uji instrumen kemampuan berpikir kritis matematis diperoleh dengan melakukan uji coba tes kemampuan berpikir kritis matematis yang terdiri dari 7 soal uraian tentang materi segiempat dan segitiga pada siswa di luar populasi penelitian. Berikut Hasil rekapitulasi uji coba tes kemampuan berpikir kritis matematis yang dapat dilihat pada Tabel 1.

Tabel 1. Analisis Hasil Uji Instrumen .

\begin{tabular}{clcccl} 
No. Butir Soal & Validitas & Uji Reabilitas & $\begin{array}{c}\text { Tingkat } \\
\text { Kesukaran }\end{array}$ & $\begin{array}{c}\text { Daya } \\
\text { Pembeda }\end{array}$ & Kesimpulan \\
1 & Valid & & Sedang & Cukup & Digunakan \\
2 & Valid & & Sedang & Baik & Digunakan \\
3 & Valid & Reliabel & Sedang & Cukup & Digunakan \\
4 & Valid & & Sedang & Baik & Digunakan \\
5 & Valid & & Sedang & Cukup & Digunakan \\
6 & Valid & & Sedang & Cukup & Digunakan \\
7 & Valid & & Sukar & jelek & Tidak Digunakan \\
\hline
\end{tabular}

Uji kemampuan berpikir kritis matematis siswa digunakan untuk melihat seberapa besar pengaruh media pembelajaran geometri berbasis etnomatematika pada kelas eksperimen dan pendekatan pembelajaran konvensional yang merupakan treatment pada kelas kontrol terhadap kemampuan berpikir kritis matematis siswa. Adapun data hasil posttest kemampuan berpikir kritis matematis siswa pada materi segiempat dan segitiga terangkum dalam Tabel 2.

Tabel 2. Deskripsi Data Kemampuan Berpikir Kritis Matematis Siswa

\begin{tabular}{|c|c|c|c|c|c|c|c|}
\hline \multirow[t]{2}{*}{ Kelompok } & \multirow[t]{2}{*}{$\mathbf{X}_{\text {maks }}$} & \multirow[t]{2}{*}{$\mathbf{X}_{\min }$} & \multicolumn{3}{|c|}{$\begin{array}{c}\text { Ukuran Tendensi } \\
\text { Sentral }\end{array}$} & \multicolumn{2}{|c|}{$\begin{array}{c}\text { Ukuran variasi } \\
\text { kelompok }\end{array}$} \\
\hline & & & $\bar{x}$ & $\mathbf{M}_{\mathbf{0}}$ & $\mathbf{M e}_{\mathbf{e}}$ & $\mathbf{R}$ & Sd \\
\hline Eksperimen & 94,44 & 66,67 & 86,57 & 94,44 & 88,89 & 27,77 & 8,62 \\
\hline kontrol & 94,44 & 55,56 & 77,33 & 83,33 & 77,78 & 38,88 & 11,32 \\
\hline
\end{tabular}

Berdasarkan Tabel 2 dapat dilihat bahwa 86,57 dan kelas kontrol sebesar 77,33 nilai posttest dengan nilai tertinggi 94,44 pada kelas ekpserimen dan kelas kontrol, sedangkan nilai terendah untuk kelas eksperimen adalah 66,67 dan kelas kontrol adalah 55,56. Ukuran tendensi sentral yang meliputi rata-rata kelas (mean) untuk kelas eksperimen sebesar sementara untuk nilai tengah kelas eksperimen yaitu sebesar 88,89 dan kelas kontrol sebesar 77,78 sedangkan modus pada kelas eksperimen adalah sebesar 94,44 dan kelas kontrol sebesar 83,33. Ukuran variansi kelompok yang meliputi jangkauan atau rentang untuk kelas 
eksperimen adalah 27,77 dan kelas kontrol adalah 38,88. Simpangan baku kelas eksperimen sebesar 8,62 dan kelas kontrol sebesar 11,32. Dengan demikian dapat disimpulkan bahwa deskripsi data skor posttest kemampuan berpikir kritis matematis siswa mempunyai perbedaan antara kelas eksperimen dan kelas kontrol.

Uji normalitas yang digunakan dalam penelitian ini adalah liliefors dengan taraf signifikasi 5\%. Uji normalitas dilakukan pada data variabel terikat yaitu kemampuan berpikir kritis matematis. Uji normalitas data kemampuan berpikir kritis matematis dilakukan terhadap masing-masing kelompok yaitu kelompok eksperimen dan kelompok kontrol. Hasil uji normalitas skor kemampuan berpikir kritis matematis dapat dilihat dalam Tabel 3.

Tabel 3. Hasil Uji Normalitas Kemampuan Berpikir Kritis Matematis Siswa

\begin{tabular}{lcccccc}
\multicolumn{1}{c}{ Kelas } & $\overline{\boldsymbol{x}}$ & \multicolumn{1}{c}{ Sd } & A & Lhitung & Ltabel & Keputusan Uji \\
Eksperimen & 86,341 & 8,663 & 0,05 & 0,174 & 0,178 & Data Berditribusi Normal \\
Kontrol & 77,333 & 11,554 & 0,05 & 0,101 & 0,173 & Data Berditribusi Normal \\
\hline
\end{tabular}

Berdasarkan pada Tabel 3 dapat diketahui bahwa posttest kemampuan berpikir kritis matematis matematis kelas eksperimen memiliki rata-rata (mean) sebesar 86,341 dan nilai simpangan baku 8,663 kemudian didapat Litung $=0,174$ yaitu nilai tertinggi, dengan taraf signifikasi $\alpha=0,05$ maka diperoleh Lhitung $<$ Ltabel, sehingga dsimpulkan sampel berasal dari populasi yang berdistribusi normal. Hasil posttest kemampuan berpikir kritis matematis kelas kontrol memiliki rata-rata (mean) sebesar 77,333 dan nilai simpangan baku 11,554 kemudian didapat Lhitung $=0,101$ yaitu nilai tertinggi, dengan taraf signifikasi $\alpha=$ 0,05 maka diperoleh Lhitung< Ltabel, sehingga disimpulkan sampel berasal dari populasi yang berdistribusi normal.

Uji homogenitas yang dilakukan pada penelitian ini adalah uji dua varians. Rangkuman hasil uji homogenitas posttest dapat dilihat pada Tabel 4.

Tabel 4. Uji Homogenitas

\begin{tabular}{lllll}
\hline Kelompok & $\mathrm{N}$ & $\mathrm{F}_{\text {hitung }}$ & $\mathrm{F}_{\text {tabel }}$ & Keputusan \\
Eksperimen & 24 & 1,724 & 1,993 & Data Homogen
\end{tabular}

kontrol 25
terkumpul dapat

Setelah data terkumpul dapat dilakukan penganalisaan data yang digunakan untuk menguji hipotesis. Pengujian hipotesis menggunakan uji kesamaan dua rata-rata, rumus statistik yang digunakan adalah rumus uji-t parametrik. Alasan mengapa digunakan uji-t pada posttest adalah untuk mengetahui adakah perbedaan

Tabel 5. Uji Hipotesis

\begin{tabular}{llllll}
\hline Kelompok & Rata-rata & Varians & $F_{\text {hitung }}$ & $\mathrm{F}_{\text {tabel }}$ & Keputusan \\
Eksperimen & 86,573 & 77,573 & 3,138 & 2,011 & $\mathrm{H}_{0}$ ditolak \\
kontrol & 77,333 & 133,501 & & & \\
\hline
\end{tabular}

Berdasarkan uji hipotesis posttest kemampuan berpikir kritis matematis pada materi segiempat dan segitiga dapat dilihat bahwa thitung $=3,138>$ ttabel $=2,011$ ini berarti pada taraf signifikasi $\alpha=0,05$ dapat disimpulkan terdapat pengaruh kemampuan berpikir kritis matematis siswa antara kelas eksperimen dan kontrol. Jika tidak ada perbedaan maka dapat disimpulkan bahwa siswa memiliki kemampuan berpikir kritis matematis yang sama atau rata. Hasil uji hipotesis yang dilakukan dapat dilihat pada Tabel 5.

media pembelajaran geometri berbasis etnomatematika terhadap kemampuan berpikir kritis matematis siswa. Selain dalam bentuk tabel hasil uji hipotesis tes posttest disajikan juga dalam bentuk grafik yang terlihat pada Gambar 2. 
Desimal, 1 (1), 2018 - 21

Wiwin Sumiyati, Netriwati, Rosida Rakhmawati

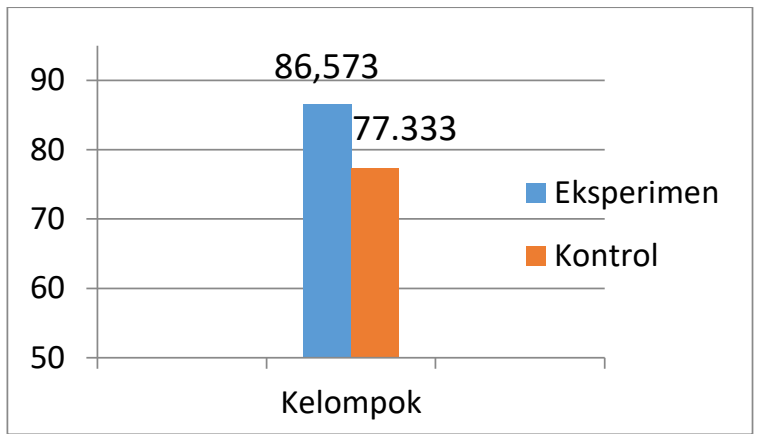

Gambar 2. Kurva Perbandingan

Berdasarkan Gambar 1 dapat diketahui bahwa kedua kelompok memiliki rata-rata yang jauh beda yaitu kelompok eksperimen sebesar 86,573 dan kelompok kontrol sebesar77,33. Dengan demikian dapat disimpulkan bahwa kemampuan berpikir kritis matematis siswa dengan menggunakan media pembelajaran geometri berbasis etnomatematika lebih baik dari model pembelajaran konvensional.

\section{SIMPULAN DAN SARAN}

Berdasarkan hasil analisis data dan pembahasan dapat disimpulkan bahwa terdapat perbedaan kemampuan berpikir kritis antara kelas eksperimen yang diberi perlakuan dan kelas kontol yang tidak diberi perlakuan. Artinya terdapat pengaruh penggunaan media pembelajaran geometri berbasis etnomatematika terhadap kemampuan berpikir kritis matematis siswa.

Saran untuk penelitian selanjutnya mengembangkan penelitian dengan terlebih dahulu mengembangkan modul dengan pendekatan lainnya dengan berbasis etnomatematika. Penambahan variabel kemampuan afektif siswa pun dapat ditambahkan untuk meninjau kemampuan kognitif siswa dalam mengukur pengaruh yang diberikan oleh modul yang dikembangkan.

\section{DAFTAR PUSTAKA}

Danoebroto, S. W. (2016). Studi Kulaitatif Tentang Guru Matematika Di SMP Sekitar Candi Borobudur Dalam Melaksanakn Pembelajaran Yang Responsif Budaya. Journal of Mathematics And Education, 3.

Edy, T. (2013). Pengembangan Pembelajaran Matematika Sekolah Dengan Pendekatan Etnomatematika Berbasis Budaya Lokal Sebagai Upaya Untuk Meningkatkan Kualitas Pembelajaran Matematika Di Sekolah. Prosiding Seminar Nasional Matematika dan Pendidikan Matematika Jurusan Pendidikan Matematika FMIPA UNY. Yogyakarta.

Karim, A. (2011). Penerepan Metode Penemuan Terbimbing Dalam Pembelajaran Matematika Untuk Meningkatkan Pemahaman Konsep dan Kemampuan Berfikir Kritis Siswa Sekolah Dasar. 21-31.

Manfaat, B., \& Anasha, Z. Z. (2016). Kemampuan Berpikir Kritis Matematik Siswa Dengan Menggunakan Graded Response Models (GRM). Seminar Nasional Matematika dan Pendidikan Matematika, Cirebon: FMIPA UNY .

Novalia, \& Syazali, M. (2014). Olah Data Penelitian Pendidikan. Bandar Lampung: Anugrah Utama Raharja (AURA). 
Desimal, 1 (1), 2018 - 22

Wiwin Sumiyati, Netriwati, Rosida Rakhmawati

Putra, F. G. (2017). Eksperimentasi Pendekatan Kontekstual Berbantuan Hands On Activity (HoA) Terhadap Kemampuan Pemecahan Masalah Matematis. Al-Jabar : Jurnal Pendidikan Matematika, 8, 73-80.

Sari, A. W., Farida, \& Putra, F. G. (2017).

Pengembangan

Media

Pembelajaran Berbantuan Web

Dengan Pendekatan

Etnomatematika Pada Pokok

Bahasan Bangun Ruang Sisi Datar.

In Prosiding Seminar Nasional

Matematika dan Pendidikan Matematika, 1.

Sirate., F. S. (2012). Impelementasi Etnomatematika Dalam Pembelajaran Matematika Pada Jenjang Pendidikan Sekolah Dasar. Jurnal Lentera Pendidikan, 15.

Sugiyono. (2014). Metode Penelitian Kuantitatif, Kualitatif dan $R \& D$. Bandung: Alfabeta.

Sukring. (2016). Pendidik Dalam Pengembangan Kecerdasan Peserta Didik (Analisis Persfektif Pendidikan Islam). Tadris : Jurnal
Keguruan dan Ilmu Tarbiyah, 1, 6980.

Widyawati, S. (2017). Pengaruh Kemampuan KoneksiI Matematis Siswa TEerhadap Prestasi Belajar Matematika Ditinjau Dari Gaya Belajar Pada Materi bangun Datar Siswa kelas IX SMP di Kota Metro. Iqra', 1, 47-67.

Yuliyanto, \& Jailani. (2014). Pengembangan Perangkat Pembelajaran Geometri Smpmenggunakan Metode Penemuan Terbimbingpada Kelas VIII Semester II. JRPM (Jurnal Riset Pendidikan Matematika), 1, 127138.

Yusnita, I., Masykur, R., \& Suherman. (2016). Modifikasi Model Pembelajaran Gerlach dan Ely Melalui Integrasi Nilai-Nilai Keislaman Sebagai Upaya Meningkatkan Kemampuan Representasi Matematis. Al-Jabar: Jurnal Pendidikan Matematika, 2938. 